\title{
Unhealthy food advertising directed to children on New Zealand television: extent, nature, impact and policy implications
}

\author{
Stefanie Vandevijvere*, Alanna Soupen and Boyd Swinburn \\ The University of Auckland, School of Population Health, Tamaki Innovation Campus, Private Bag 92019, \\ Auckland 1142, New Zealand
}

Submitted 17 November 2016: Final revision received 18 March 2017: Accepted 4 April 2017: First published online 26 May 2017

\begin{abstract}
Objective: To comprehensively assess the extent, nature and impact of unhealthy food advertising targeted to children on New Zealand television.

Design: Four weekdays and four weekend days were randomly selected over the period June-August 2015. Programming was recorded from 06.00 to 00.00 hours (midnight), for a total of $432 \mathrm{~h}$. Audience ratings were used to identify children's peak viewing times.

Setting: New Zealand.

Subjects: The three major free-to-air channels.

Results: The majority of foods advertised ( $n$ 1807) were unhealthy; $68.5 \%$ of food advertisements included at least one food not permitted to be marketed to children according to the WHO nutrient profiling model. The mean hourly rate of unhealthy food advertising was 9.1 (SD 5.2). One-third of unhealthy food advertisements included a promotional character and one-third a premium offer. About $88 \%$ of unhealthy food advertisements were shown during children's peak viewing times. If unhealthy food advertisements were to be restricted during times when at least $25 \%$ of children are watching television, this would reduce the average unhealthy food advertising impact by $24 \%$ during weekdays and $50 \%$ during weekend days, and if the WHO instead of the current nutrient profiling model were used to restrict unhealthy food advertising to children, the average impact would be reduced by $24 \%$ during weekdays and $29 \%$ during weekend days.

Conclusions: Current self-regulation is ineffective in protecting children from exposure to unhealthy food advertising on television. The WHO nutrient profiling model needs to be used to restrict unhealthy food advertising, especially during children's peak viewing times.
\end{abstract}

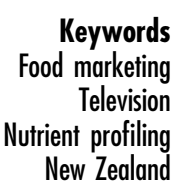

New Zealand's rates of childhood obesity are unacceptably high. According to the 2014/2015 New Zealand Health Survey, a third of New Zealand children aged 2-14 years are obese (11\%) or overweight (22\%), the third highest rates among countries belonging to the Organisation for Economic Co-operation and Development ${ }^{(1)}$. Furthermore, $30 \%$ of Pacific children and 15\% of Māori children are classified as obese, and children living in the most deprived areas of New Zealand are five times more likely to be obese than those in the least deprived areas ${ }^{(1)}$. Children who are overweight or obese are more likely to become obese adults and to develop non-communicable diseases like diabetes and CVD earlier in life ${ }^{(2)}$.

One of the key recommendations in the recent final report of the WHO's Commission on Ending Childhood Obesity, chaired by the Chief Science Advisor to the Prime Minister in New Zealand, has been to implement comprehensive restrictions on the marketing of unhealthy foods and non-alcoholic beverages (hereafter "unhealthy food marketing') to children, including the monitoring and evaluation of these marketing efforts ${ }^{(2)}$. Previous research, including several systematic reviews, has shown that exposure to food marketing influences children's brand recognition, purchasing requests and food preferences ${ }^{(3-6)}$. In May 2010, 192 Member States endorsed Resolution WHA63.14 to restrict the marketing of unhealthy foods to children and adolescents globally, but progress by governments and food companies in implementing such restrictions has been very patchy to date ${ }^{(7)}$.

In New Zealand, food advertising to children is selfregulated by the industry, involving several bodies including the Commercial Approvals Bureau (CAB), the Advertising Standards Authority (ASA), individual broadcasters and food and beverage companies. Television and radio advertisements for both food and non-food products have to be screened by the $\mathrm{CAB}$ before being aired. The 
screening process for airing food advertisements during designated children's programming times (defined by individual broadcasters and not the CAB) is governed by two codes of practice developed by the ASA. These are the Children's Code for Advertising Food $^{(8)}$ and the Code for Advertising to Children, which only apply to children between 0 and 13 years of age. To be aired during designated children's programming times, it is recommended that foods advertised meet the New Zealand Ministry of Health criteria for an 'everyday' or 'sometimes' food $^{(9,10)}$.

'Everyday' foods are foods from the four core food groups (breads, rice and cereals, fruits and vegetables, meat, fish and poultry and dairy), while 'sometimes' foods are higher in fat, sugar and salt and should not dominate children's diets ${ }^{(10)}$. Under the codes, 'occasional' foods ('junk' foods high in fat, salt and sugar, low in nutritional value and suitable for occasional consumption only) can only be advertised during children's programming times under the assessment of independent nutritionists ${ }^{(9)}$. Previous research suggests that this system has been ineffective, with previous studies across several media platforms reporting that the majority of food marketing in New Zealand is for unhealthy or occasional foods ${ }^{(11)}$. In addition, internationally, it has been shown that industry self-regulation has been ineffective to date to reduce exposure of children to unhealthy food marketing ${ }^{(12)}$.

Several major weaknesses exist in New Zealand's current self-regulatory system, such as the lack of provisions to reduce the total volume of unhealthy food advertising seen by children and the definition of 'children's viewing times', which includes children's programmes but not children's peak viewing times. Recently the ASA codes have undergone a review and a new draft code has been proposed ${ }^{(13)}$, including the following new provision: 'Occasional Food and Beverage Product advertisements must not be screened, broadcast, published or displayed in any media or setting where more than $25 \%$ of the expected audience are children.'

Previous studies on television food advertising in New Zealand are old and investigated only selected hours during the day ${ }^{(14-16)}$. The aims of the present study were to comprehensively assess the extent, nature and impact of unhealthy food advertising targeted to children on New Zealand television and to derive key policy implications. Impact refers to the number of children viewing an advertisement, where one impact is equivalent to one child viewing one showing of an advertisement.

\section{Methods}

The methods follow the recommendations by the International Network for Food and Obesity/non-communicable diseases Research, Monitoring and Action Support (INFORMAS) for monitoring unhealthy food marketing to children $^{(17)}$.

\section{Channels and bours and days}

The three major free-to-air channels (those with the highest children's audience) in New Zealand were selected for the study. These were ONE (TV1), TV 2 (TV2) and Three (TV3). Eight days (four weekdays and four weekend days, including two Saturdays and two Sundays) were randomly selected over a 3-month period from 1 June 2015 to 31 August 2015, excluding school holiday periods. Television programming was recorded from 06.00 to 00.00 hours (midnight) for each day, with a total of $432 \mathrm{~h}$ of television recorded.

\section{Audience measurement data}

Audience rating data (the number of children watching a particular channel for each half-hour of the day) was obtained from the market research company A.C. Nielsen in order to identify children's peak viewing times (Table 1). Audience rating data were obtained for each 30 min block between 06.00 and 00.00 hours (midnight). The average audience ratings for weekdays, Saturdays and Sundays during the sampled three months (June-August 2015), excluding school holiday periods, were used. Audience ratings for all three channels were reported separately and aggregated ratings across all channels (including channels not included for monitoring) were also obtained. Separate estimates were obtained for the total population (5-13-year-olds and 14-18-year-olds reported separately) and for Māori and Pacific populations (5-18-year-olds). Children's and adolescents' peak viewing times were defined as the hours for which the number of children/ adolescents watching television (all channels combined) was: (i) greater than a quarter of the maximum child/adolescent audience rating for the day ${ }^{(18)}$; (ii) greater than $50 \%$ of the maximum child/adolescent audience rating for the day; and (iii) the hours for which more than $25 \%$ of all New Zealand children/adolescents were watching television.

\section{Recording and coding food advertisements}

Recordings for the eight sampled days were obtained from the University of Auckland's satellite recording service, UniSat. UniSat provided bulk downloads of recordings for a day at a time, which were made available on a designated server. Once recordings were downloaded by the researcher, the video editing software Quicktime was used to forward through recordings between advertisements.

Advertisements were coded as advertisements for food products, food companies/brands ('advertisement without specific food product depicted') or non-food products. If a food or food company/brand advertisement was shown, further details about the advertisement were recorded and included: the type of advertiser (e.g. supermarket, food manufacturer, restaurant/takeaway or other non-food company); a description of the food product(s) advertised; and the use of any promotional strategies (including cartoon/company-owned characters, 
licensed characters, amateur sportspersons, non-sports celebrities, movie tie-ins, famous sportspersons, 'for kids' messaging) or premium offers (including game and app downloads, contests, 'Pay 2 take 3' or other, '20\% extra' or other, limited edition offers/products, social charities, gifts or collectibles, price discounts, loyalty programmes).

\section{Classification of foods advertised as bealthy/ unbealtby}

Food products were classified according to two systems: the WHO-Europe (WHO-EU) nutrient profiling system for restricting unhealthy food marketing to children (permitted/not permitted to be marketed to children) ${ }^{(19)}$ and the New Zealand Ministry of Health Food and Beverage Classification system (everyday, sometimes or occasional) ${ }^{(10)}$. The WHO-EU nutrient profiling model was selected because it is specifically designed for the purpose of restricting marketing of unhealthy foods to children, was developed following extensive consultation with European member states and is based on three nutrient profile models currently in use in Europe for restricting marketing to children. In addition, it includes fresh (unpackaged) foods, and has been recommended as the best system to restrict unhealthy food marketing to children in New Zealand based on a comparison of three nutrient profile models applied on a database of more than 13000 packaged food products ${ }^{(20)}$. For all advertisements, except those shown by restaurants and takeaways where combo meals were advertised, if an advertisement promoted more than one food product (e.g. in the case of supermarket advertisements), then each food was classified separately. A food advertisement was considered unhealthy (i.e. occasional or restricted to be marketed to children) if it included at least one unhealthy food. For restaurants and takeaways where combo meals (e.g. burger, sundae and large soft drink for \$NZ12) were shown, the entire meal was coded as one item. The New Zealand Nutritrack database ${ }^{(21)}$ with food composition data on packaged food products was used to determine the nutrient profile of the food products advertised.

\section{Definition of advertising targeted to children}

The Obesity Policy Coalition's definition of 'targeted to children' was used. This is a comprehensive definition that considers the advertisement's intended audience, the proportion of children making up the advertisement's actual audience and where the advertisement is placed ${ }^{(22)}$. In the present study, specifically focusing on television advertising, food and food/company brand advertisements were considered as being targeted to children if they met at least one of the following criteria: (i) shown during designated children's programmes; (ii) shown during children's peak viewing times (as defined in Table 1); and (iii) contained promotional strategies or premium offers known to appeal to children, such as cartoon/company-owned characters (e.g. M\&Ms), licensed characters (e.g. Dora the Explorer), 'for kids' messaging, movie tie-ins (e.g. Minions), and gifts or collectables (e.g. Disney Pixar collectables, Minions toys).

\section{Data analysis}

Data were analysed using the statistical software package IBM SPSS Statistics version 22. Estimates were produced for the levels of food and unhealthy food advertising per hour, by food company/brand and by type of advertiser, and the levels of unhealthy food advertising with promotional characters/premium offers and targeted at children. The average 'impact' of unhealthy food advertising was calculated by weekday and weekend day and for children (5-13 years) and adolescents (14-18 years) separately. The average impact is equal to the average number of children watching (channel-specific audience data used) times the average of the sum of unhealthy food advertisements per half-hour. Plots were drawn to show the extent of unhealthy food advertising over the day $v$. the change in child audience ratings over the day. Analyses including both weekdays and weekend days were weighted to account for their unequal probability of selection. Weights were derived through calculating the inverse of the probability of selection for weekdays and weekend days during the three months of the study. The weights (1.39 for weekdays and 3.54 for weekend days) were divided by the mean weight of all cases for each different analysis performed.

\section{Results}

\section{Children's television viewing patterns}

TV2 was the most popular channel among 5-13-year-olds and 14-18-year-olds, followed by TV3 and TV1. Viewing patterns were similar for both Māori and Pacific children and non-Māori non-Pacific children, peaking in the morning and evenings on weekdays and in the evenings on weekends. Peak viewing times occurred outside children's programming times (Table 1, Figs 1 and 2). While the proportion of Māori and Pacific children watching television at any time tended to be higher than that of non-Māori and non-Pacific children, this was not examined any further because of the small sample size of Māori and Pacific children used by A.C. Nielsen to determine the audience ratings.

The only times of the day when more than $25 \%$ of the total New Zealand children aged 5-13 years were watching were 18.30-19.30 hours on weekdays and 18.0020.00 hours (Saturday) and 18.30-20.30 hours (Sunday) on weekend days. There were no times during which at least $25 \%$ of the total New Zealand adolescents aged 14-18 years were watching television (Table 1).

\section{Total and unbealthy food advertising rates}

In total, 10471 advertisements were recorded over the eight days. About $17 \cdot 3 \%$ of those advertisements were for 


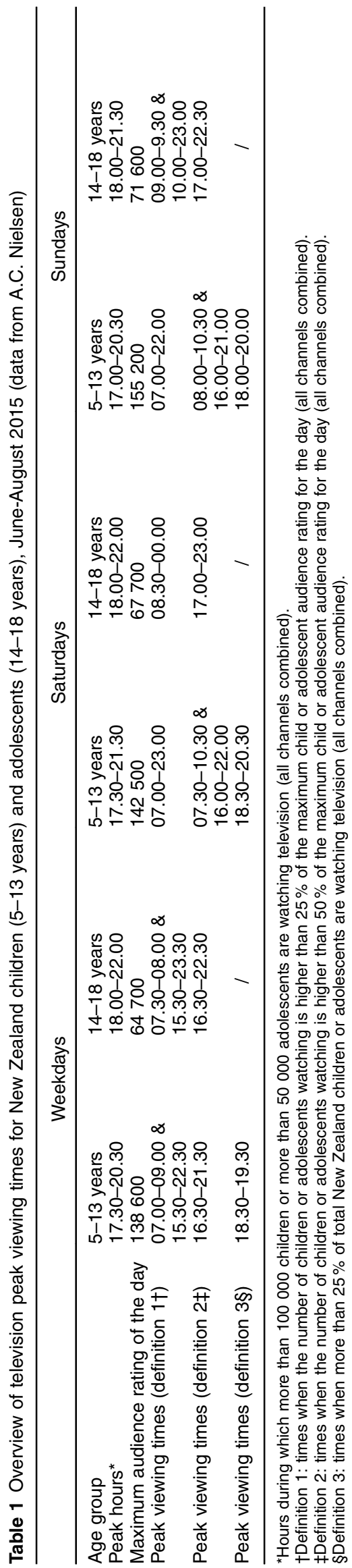

food products or brands/companies. The percentage of food brand/company advertising (without depicting a specific food in the advertisement) was low (2\%). About $37 \%$ of food advertisements displayed a promotional character and about $37 \%$ included a premium offer (Table 2). The most popular promotional strategy used was the 'for kids' strategy (39\%), where children were shown in the advertisement or the product was specifically directed at children in the advertisement's text, audio or in print on the product packaging. This was followed by the use of non-sports celebrities (21\%) and cartoon/companyowned characters $(17 \%)$. The most popular type of premium offer used was price discounts (39\%), followed by limited edition offers/products (30\%), loyalty programmes (16\%) and gifts or collectables ( $12 \%$; data not shown). About $55.6 \%$ of all promotional characters used in the advertisements were specifically targeted at children, while only $4.2 \%$ of premium offers were specifically targeted at children.

Of all food advertisements aired on television ( $n$ 1807), $50.5 \%$ included at least one occasional food and $68.5 \%$ included at least one food not permitted to be marketed to children according to the WHO-EU nutrient profiling system (Table 2). About one-third of unhealthy food advertisements included a promotional character and one-third of unhealthy food advertisements included a premium offer. The proportion of unhealthy food advertisements displayed during designated children's programmes was very low and occurred almost exclusively on weekends, while the proportion of unhealthy food advertisements during children's peak viewing times (as per definition 1) was very high at about $88 \%$ and higher during weekend than week peak viewing times. Almost all unhealthy food advertisements shown on New Zealand television were specifically targeted at children (Table 2). The mean hourly rate of food advertising was 13.3 (SD 7.4) and the mean hourly rate of unhealthy food advertising was 6.7 (SD 4.1) for occasional foods or 9.1 (SD 5.2) for foods restricted to be marketed to children by the WHO (Table 3).

TV2 had higher levels of food advertising than the other two channels. About $22 \%$ of all advertisements on TV2 ( $n$ 3207) were food advertisements, followed by $16 \%$ on TV3 ( $n$ 3808) and $14 \%$ on TV1 ( $n$ 3456). TV2 also had higher levels of unhealthy food advertising compared with the other channels. Using the Ministry of Health and WHO-EU nutrient profiling systems, respectively $58.7 \%$ and $76.5 \%$ of food advertisements on TV2 were classified unhealthy, $47 \cdot 8 \%$ and $63.1 \%$ on TV3 were classified as unhealthy and $45.7 \%$, and $64.5 \%$ on TV1 were classified as unhealthy (data not shown).

\section{Unbealtby food advertising by advertiser type and} company or brand

The three types of food advertisers with the highest percentage of food advertisements shown on television were 


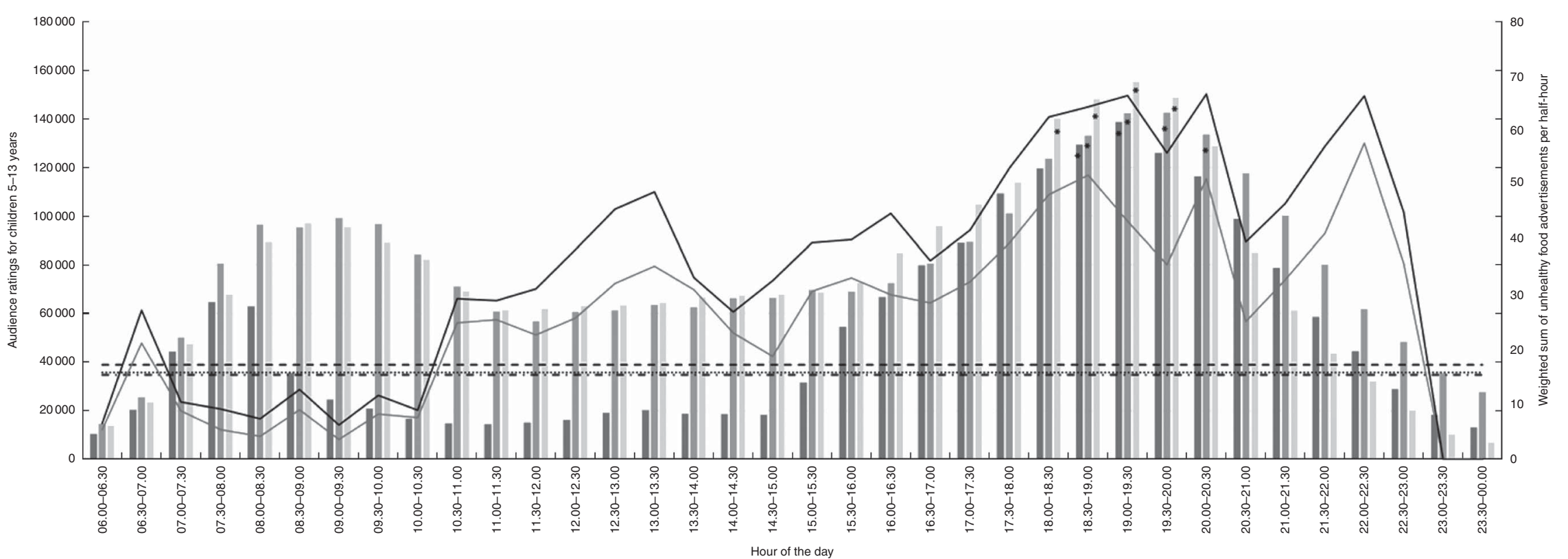

Fig. 1 Weighted sum of unhealthy food advertisements (931 occasional food advertisements, 1243 food advertisements restricted to be marketed to children by WHO) and audience ratings (all television channels combined) per half-hour (eight recording days, three major free-to-air channels) for children aged 5-13 years, New Zealand, June-August 2015. Food advertisements restricted to be marketed to children by the WHO-Europe nutrient profiling system ${ }^{(19)}(-)$; occasional food advertisements according to New Zealand Ministry of Health Food and Beverage Classification system ${ }^{(10)}(-)$; hours during which more than $25 \%$ of total New Zealand adolescents are watching television $\left({ }^{*}\right)$; audience ratings on weekdays ( $\square$ ); audience ratings on Saturdays ( $\square$ ); audience ratings on Sundays ( $\square$ ); $25 \%$ of maximum child audience rating of the day - weekdays (..... ); $25 \%$ of maximum child audience rating of the day - Saturdays $(\ldots \ldots) ; 25 \%$ of maximum child audience rating of the day - Sundays (- . - - -) 


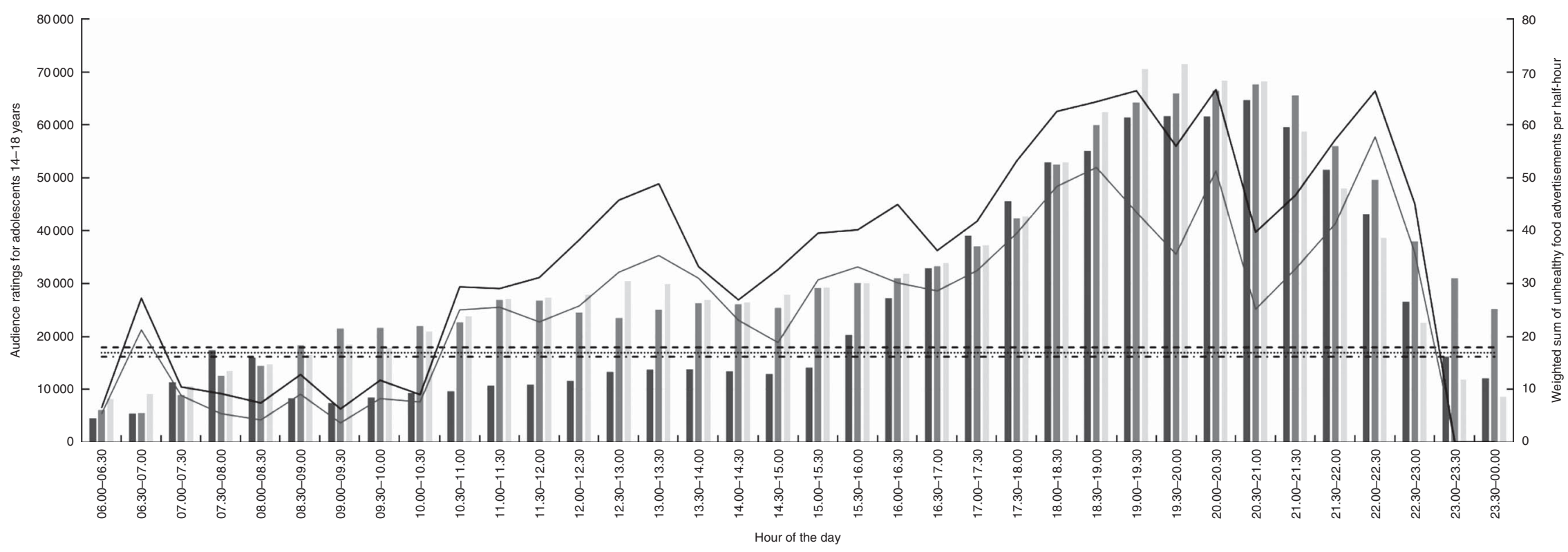

Fig. 2 Weighted sum of unhealthy food advertisements (931 occasional food advertisements, 1243 food advertisements restricted to be marketed to children by WHO) and audience ratings (all television channels combined) per half-hour (eight recording days, three major free-to-air channels) for adolescents aged 14-18 years, New Zealand, June-August 2015. Food advertisements restricted to be marketed to children by the WHO-Europe nutrient profiling system ${ }^{(19)}(-)$; occasional food advertisements according to New Zealand Ministry of Health Food and Beverage Classification system ${ }^{(10)}\left(-\frac{1}{)}\right.$; hours during which more than $25 \%$ of total New Zealand adolescents are watching television $(*)$; audience ratings on

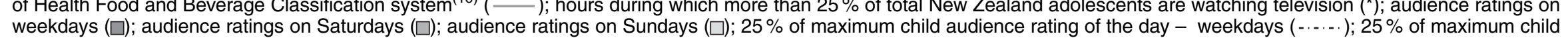
audience rating of the day - Saturdays ( $\cdots$ ) $; 25 \%$ of maximum child audience rating of the day - Sundays (- - - - -) 
Table 2 The extent and nature of unhealthy food advertising on television in New Zealand (all channels combined, eight recording days, three major free-to-air channels), June-August 2015

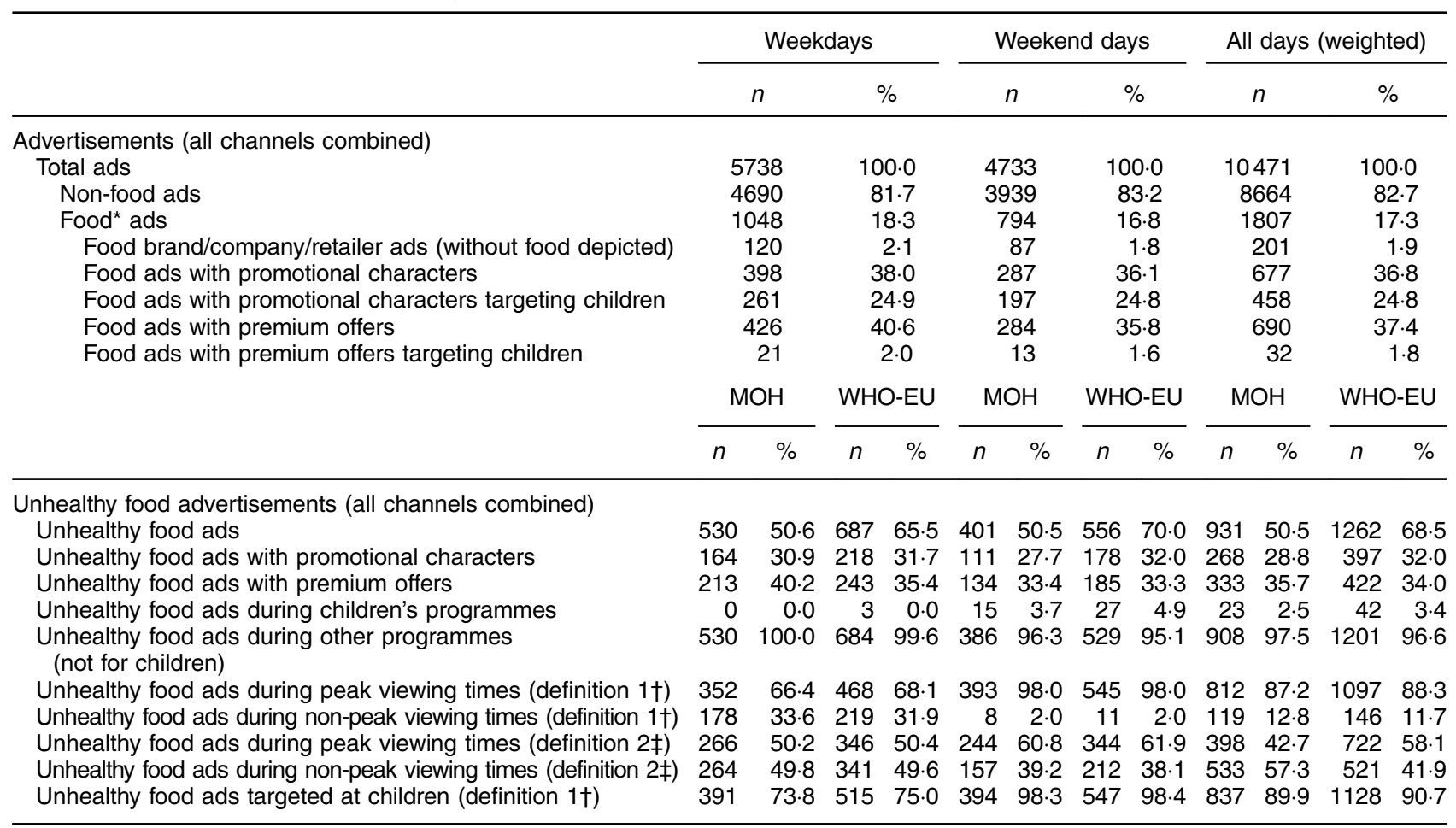

$\mathrm{MOH}$, New Zealand Ministry of Health Food and Beverage Classification System ${ }^{(10)}$ (unhealthy foods = occasional foods); WHO-EU, WHO-Europe nutrient profile model ${ }^{(19)}$ (unhealthy foods $=$ foods restricted to be marketed to children).

*Including alcohol.

†Definition 1: times when the number of children or adolescents watching is higher than $25 \%$ of the maximum child or adolescent audience rating for the day (all channels combined).

¥Definition 2: times when the number of children or adolescents watching is higher than $50 \%$ of the maximum child or adolescent audience rating for the day (all channels combined).

food or beverage manufacturers, restaurants or takeaways and supermarkets or other retailers. They contributed the most to unhealthy food advertising, together accounting for about $98 \%$ of all unhealthy food advertisements shown according to both the Ministry of Health and WHO-EU nutrient profiling systems. The remaining $2 \%$ of foods were advertised by other (non-food) companies. About $51.4 \%$ of foods were advertised by food and beverage manufacturers, while $11.6 \%$ of foods were advertised by supermarkets or other retailers, and $23.9 \%$ by fastfood, restaurant or takeaway outlets. The top fifteen companies or brands that contributed most to unhealthy food advertising and unhealthy food advertising targeted to children on television in New Zealand are given in Table 4. Two out of three of New Zealand's major supermarket chains appear on the list, along with the popular fast-food chains McDonald's, Burger King, KFC and Domino's. Most of the unhealthy food advertisements by those companies and brands were also targeted at children, meaning being shown during children's programmes, during children's peak viewing times or including a promotional character or premium offer targeted at children within the advertisement.

\section{Unhealthy food advertising during children's programmes and peak viewing hours}

Figures 1 and 2 show how the weighted sum (weighted sum over eight recording days) of unhealthy food advertisements per hour of the day changes over the course of the day and in relation to the number of children/ adolescents watching for the different hours of the day (results displayed for weekdays, Saturdays and Sundays separately, and separately for younger children aged $5-13$ years and adolescents aged 14-18 years). They show that audience numbers peak twice during the day. Audience numbers peak first once in the morning and start to rise again around 17.00 hours in the evening, peaking again at about 19.00 hours. The evening peak is much higher than the morning peak. Unhealthy food advertising peaks twice during the day, first during the morning/early afternoon and again during the evening. The evening peaks in child audience ratings and unhealthy food advertising occur for weekdays, Saturdays and Sundays and for both children as well as adolescents (Figs 1 and 2). There are no channel restrictions in effect during those peak viewing hours. The number and proportion of unhealthy food advertisements during children's programmes are very low (Table 2). 
Table 3 Mean (SD) rates of unhealthy food advertising per hour on television in New Zealand (all channels combined, eight recording days, three major free-to-air channels), June- August 2015

\begin{tabular}{|c|c|c|c|c|c|c|c|c|c|c|c|c|}
\hline & \multicolumn{4}{|c|}{ Weekdays } & \multicolumn{4}{|c|}{ Weekend days } & \multicolumn{4}{|c|}{ All days (weighted) } \\
\hline & \multicolumn{2}{|c|}{ Mean } & \multicolumn{2}{|c|}{ SD } & \multicolumn{2}{|c|}{ Mean } & \multicolumn{2}{|l|}{ SD } & \multicolumn{2}{|c|}{ Mean } & \multicolumn{2}{|l|}{ SD } \\
\hline \multicolumn{13}{|l|}{ Food advertisements (all channels combined) } \\
\hline Non-food ads & \multicolumn{2}{|c|}{$69 \cdot 0$} & \multicolumn{2}{|c|}{21.7} & \multicolumn{2}{|c|}{61.5} & \multicolumn{2}{|c|}{29.2} & \multicolumn{2}{|c|}{63.7} & \multicolumn{2}{|c|}{$27 \cdot 3$} \\
\hline Food $^{*}$ ads & \multicolumn{2}{|c|}{$15 \cdot 4$} & \multicolumn{2}{|c|}{7.4} & \multicolumn{2}{|c|}{12.4} & \multicolumn{2}{|c|}{$7 \cdot 3$} & \multicolumn{2}{|c|}{$13 \cdot 3$} & \multicolumn{2}{|c|}{7.4} \\
\hline Food brand/company/retailer ads (without food depicted) & \multirow{2}{*}{\multicolumn{2}{|c|}{$\begin{array}{l}1.8 \\
5.9\end{array}$}} & \multicolumn{2}{|c|}{1.4} & \multicolumn{2}{|c|}{1.4} & \multicolumn{2}{|c|}{1.5} & \multicolumn{2}{|c|}{1.5} & \multicolumn{2}{|c|}{1.5} \\
\hline Food ads with promotional characters & & & \multicolumn{2}{|c|}{$3 \cdot 3$} & \multirow{2}{*}{\multicolumn{2}{|c|}{4.5}} & $3 \cdot 3$ & & 4.9 & & $3 \cdot 3$ & \\
\hline Food ads with premium offers & \multicolumn{2}{|c|}{$6 \cdot 3$} & 3.9 & & & & $3 \cdot 8$ & & $5 \cdot 0$ & & 3.9 & \\
\hline Food ads with promotional characters targeting children & $3 \cdot 8$ & & $2 \cdot 6$ & & $3 \cdot 1$ & & 2.4 & & $3 \cdot 3$ & & 2.5 & \\
\hline Food ads with premium offers targeting children & 0.3 & & 0.6 & & 0.2 & & 0.5 & & 0.2 & & 0.5 & \\
\hline & $\mathrm{MO}$ & & WHO- & -EU & $\mathrm{MOl}$ & & WHO- & -EU & $\mathrm{MOl}$ & & WHO- & -EU \\
\hline & Mean & SD & Mean & SD & Mean & SD & Mean & SD & Mean & SD & Mean & SD \\
\hline Unhealthy food advertisements (all channels combined) & & & & & & & & & & & & \\
\hline Total unhealthy food ads & $7 \cdot 8$ & 4.2 & $10 \cdot 1$ & $5 \cdot 4$ & $6 \cdot 3$ & 3.9 & $8 \cdot 7$ & $5 \cdot 1$ & $6 \cdot 7$ & $4 \cdot 1$ & $9 \cdot 1$ & $5 \cdot 2$ \\
\hline Unhealthy food ads with promotional characters & $2 \cdot 4$ & $2 \cdot 0$ & 3.2 & 2.5 & 1.7 & 1.5 & $2 \cdot 8$ & $2 \cdot 2$ & 1.9 & 1.7 & 2.9 & $2 \cdot 3$ \\
\hline Unhealthy food ads with premium offers & $3 \cdot 1$ & $2 \cdot 2$ & 3.6 & $2 \cdot 8$ & $2 \cdot 1$ & $2 \cdot 2$ & 2.9 & 2.5 & $2 \cdot 4$ & $2 \cdot 2$ & $3 \cdot 1$ & 2.6 \\
\hline Unhealthy food ads during children's programmes & 0.0 & 0.0 & 0.0 & 0.3 & $0 \cdot 2$ & $1 \cdot 1$ & 0.4 & 1.5 & 0.2 & 0.9 & 0.3 & 1.3 \\
\hline Unhealthy food ads outside children's programmes & $7 \cdot 8$ & $4 \cdot 2$ & 10.1 & $5 \cdot 5$ & $6 \cdot 0$ & 3.9 & $8 \cdot 3$ & 4.9 & $6 \cdot 6$ & 4.0 & $8 \cdot 8$ & $5 \cdot 1$ \\
\hline Unhealthy food ads during peak viewing times (definition $1 \dagger$ ) & $5 \cdot 2$ & 5.5 & 6.9 & $7 \cdot 1$ & $6 \cdot 1$ & $4 \cdot 1$ & 8.5 & $5 \cdot 3$ & 5.9 & 4.5 & $8 \cdot 0$ & 5.9 \\
\hline Unhealthy food ads outside peak viewing times (definition $1 \dagger$ ) & $2 \cdot 6$ & 3.7 & $3 \cdot 2$ & 4.5 & 0.1 & 0.7 & 0.2 & 1.0 & 0.9 & 2.4 & $1 \cdot 1$ & 2.9 \\
\hline Unhealthy food ads during peak viewing times (definition $2 \ddagger$ ) & 3.9 & 5.4 & $5 \cdot 1$ & $7 \cdot 1$ & 3.8 & 4.4 & 5.4 & $6 \cdot 1$ & 3.8 & 4.7 & $5 \cdot 3$ & 6.4 \\
\hline Unhealthy food ads outside peak viewing times (definition $2 \ddagger$ ) & 3.9 & 3.6 & $5 \cdot 0$ & 4.5 & 2.5 & 3.6 & $3 \cdot 3$ & 4.7 & 2.9 & 3.6 & $3 \cdot 8$ & 4.7 \\
\hline Unhealthy food ads targeted at children (definition $1 \dagger$ ) & 5.8 & $5 \cdot 1$ & 7.6 & $6 \cdot 6$ & $6 \cdot 2$ & 4.0 & 8.5 & 5.5 & $6 \cdot 0$ & 4.4 & 8.3 & $5 \cdot 7$ \\
\hline
\end{tabular}

$\mathrm{MOH}$, New Zealand Ministry of Health Food and Beverage Classification System ${ }^{(10)}$ (unhealthy foods = occasional foods); WHO-EU, WHO-Europe nutrient profile model ${ }^{(19)}$ (unhealthy foods = foods restricted to be marketed to children).

*Including alcohol.

†Definition 1: times when the number of children or adolescents watching is higher than $25 \%$ of the maximum child or adolescent audience rating for the day (all channels combined).

†Definition 2: times when the number of children or adolescents watching is higher than $50 \%$ of the maximum child or adolescent audience rating for the day (all channels combined).

Table 4 Top fifteen companies contributing to unhealthy (restricted to be marketed by WHO-EU) food advertising to children on television in New Zealand (all channels combined, eight recording days, three major free-to-air channels), June-August 2015

\begin{tabular}{|c|c|c|c|c|c|c|}
\hline \multirow[b]{2}{*}{ Rank } & \multirow[b]{2}{*}{ Company/brand } & \multirow[b]{2}{*}{ Company type } & \multicolumn{2}{|c|}{ Unhealthy food ads* } & \multicolumn{2}{|c|}{ Unhealthy food ads targeted at children } \\
\hline & & & $n$ & $\%$ & $n$ & $\%$ \\
\hline 1 & McDonald's & Fast food & 148 & 11.8 & 134 & 90.5 \\
\hline 2 & Burger King & Fast food & 121 & 9.7 & 110 & $90 \cdot 9$ \\
\hline 3 & Countdown & Supermarket & 74 & 5.9 & 66 & 89.2 \\
\hline 4 & KFC & Fast food & 67 & $5 \cdot 4$ & 65 & 97.0 \\
\hline 5 & Kellogg's & Packaged food/beverage & 62 & $5 \cdot 0$ & 58 & 93.5 \\
\hline 6 & Mars Inc. & Packaged food/beverage & 59 & 4.7 & 50 & 84.7 \\
\hline 7 & Nestle & Packaged food/beverage & 45 & 3.6 & 38 & 84.4 \\
\hline 8 & Whittaker's & Packaged food/beverage & 43 & 3.4 & 41 & $95 \cdot 3$ \\
\hline 9 & Wrigley & Packaged food/beverage & 41 & $3 \cdot 3$ & 36 & 87.8 \\
\hline 10 & Pepsico & Packaged food/beverage & 40 & $3 \cdot 2$ & 36 & $90 \cdot 0$ \\
\hline 11 & New World & Supermarket & 39 & 3.1 & 33 & 84.6 \\
\hline 12 & Chanui & Packaged food/beverage & 37 & 3.0 & 35 & 94.6 \\
\hline 13 & Domino's & Fast food & 30 & 2.4 & 30 & 100.0 \\
\hline 14 & Fonterra & Packaged food/beverage & 27 & $2 \cdot 2$ & 27 & $100 \cdot 0$ \\
\hline \multirow[t]{2}{*}{15} & Heinz Watties & Packaqed food/beveraqe & 23 & 1.8 & 20 & 87.0 \\
\hline & Total & & 1247 & & 1130 & \\
\hline
\end{tabular}

WHO-EU, WHO-Europe nutrient profile model ${ }^{(19)}$ (unhealthy foods = foods restricted to be marketed to children).

*Percentage out of total unhealthy food advertisements.

†Percentage of unhealthy food advertisements that are targeted at children for that particular company (excluding advertisements without foods depicted).

\section{Impact of unbealtby food advertising}

Figures 3 and 4 show the average unhealthy food advertising impact for weekdays and weekend days and separately for children and adolescents. The impact of unhealthy food advertising peaks in the evenings during which there are no channel restrictions in place. The highest average impact (256100 unhealthy advertisement impressions during weekdays and 234225 during weekend days) can be 
(a)

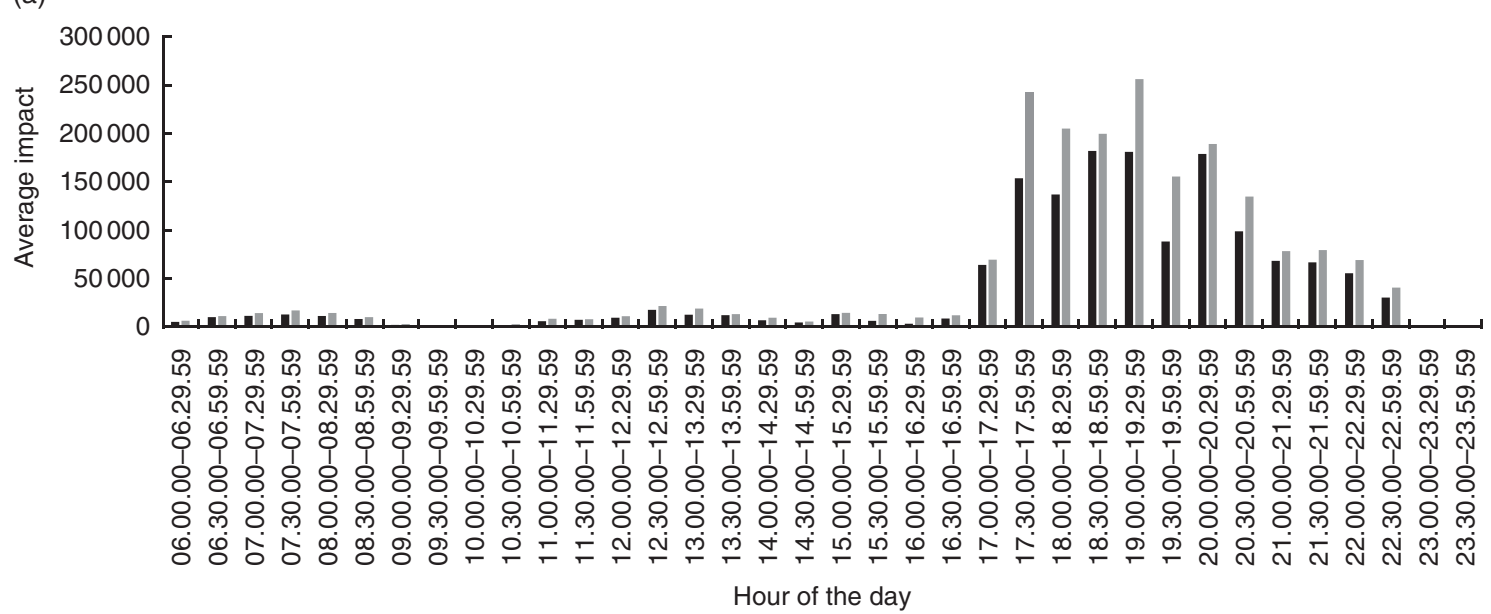

(b)

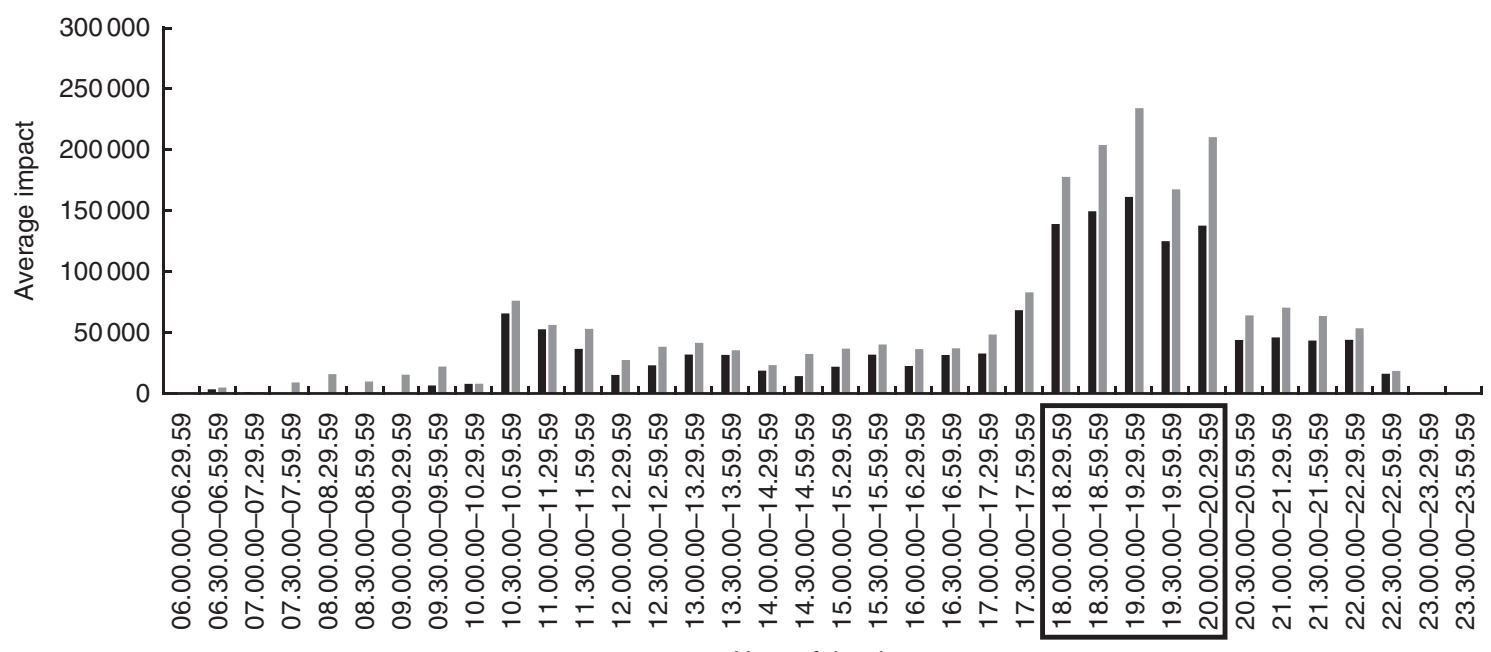

Hour of the day

Fig. 3 Unhealthy food advertising impact (number of advertisements $\times$ number of views) during (a) weekdays and (b) weekend days (all television channels combined) per half-hour (eight recording days, three major free-to-air channels) for children aged 5-13 years, New Zealand, June-August 2015. Food advertisements restricted to be marketed to children by the WHO-Europe nutrient profiling system ${ }^{(19)}(\square)$; occasional food advertisements according to New Zealand Ministry of Health Food and Beverage Classification system ${ }^{(10)}(\square)$; peak viewing times, i.e. times when more than $25 \%$ of total children are watching television ( $\square$ )

seen between 19.00 and 19.30 hours for younger children (5-13 years) and is eight- to tenfold the average impact during other hours of the day. This also allows us to look at the impact of different types of regulation that could be implemented to reduce the impact of unhealthy food advertising.

The WHO-EU nutrient profile system would be more restrictive than the Ministry of Health classification to reduce exposure of children to unhealthy food advertising, as the average total impact of unhealthy food advertising over weekdays is $29.3 \%$ higher for the WHO-EU than the Ministry of Health system for younger children and 29.6\% for older children. For weekend days, the impacts using the WHO-EU system are $24.0 \%$ and $24.0 \%$ higher for younger and older children, respectively (data not shown). If unhealthy food advertisements using either the
WHO-EU or current nutrient profiling system would be restricted during children's peak evening viewing times (18.30-19.30 hours during weekdays and 18.0020.30 hours during weekend days), which fall outside the designated children programme slots, then that would reduce the impact of unhealthy food advertising by about $24 \%$ during weekdays for the younger children and $50 \%$ during weekend days (data not shown). These restrictions would currently not apply for older children.

\section{Discussion}

The findings of the present study suggest that children are exposed to a food marketing environment on television that is largely unhealthy and persuasive ${ }^{(23,24)}$ 
(a)

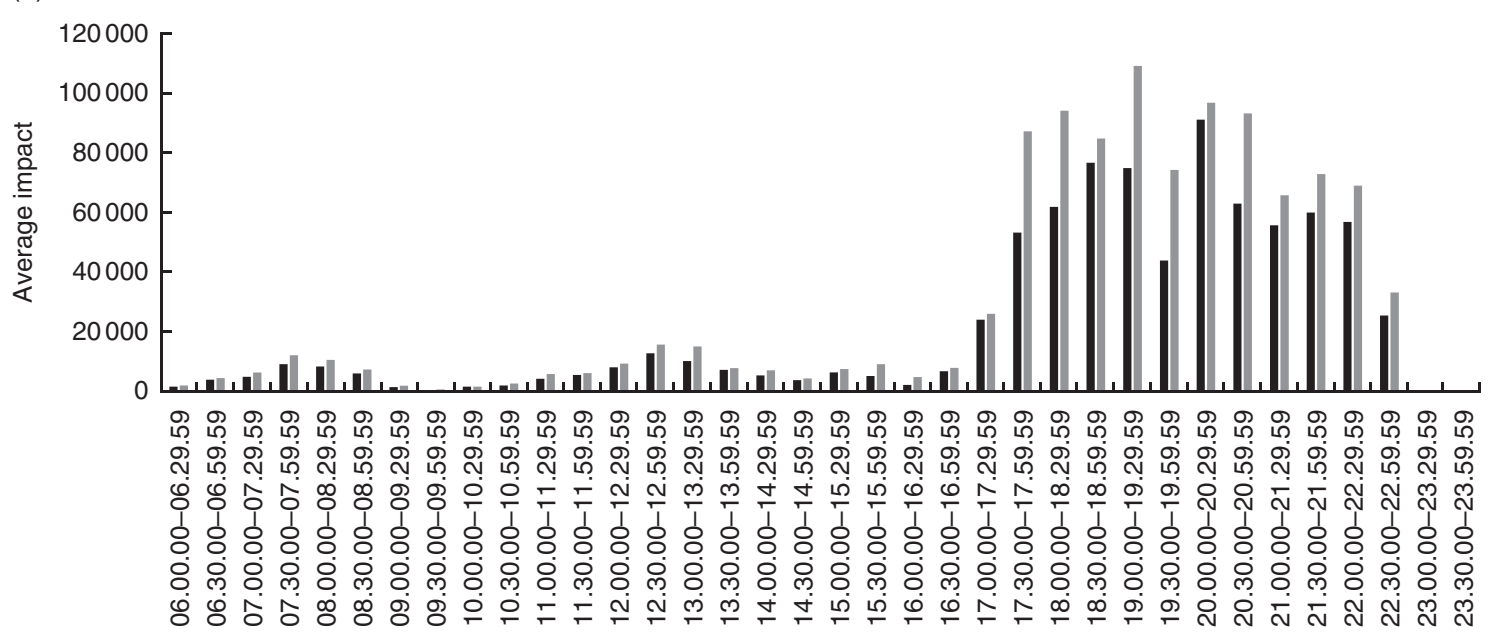

Hour of the day

(b)

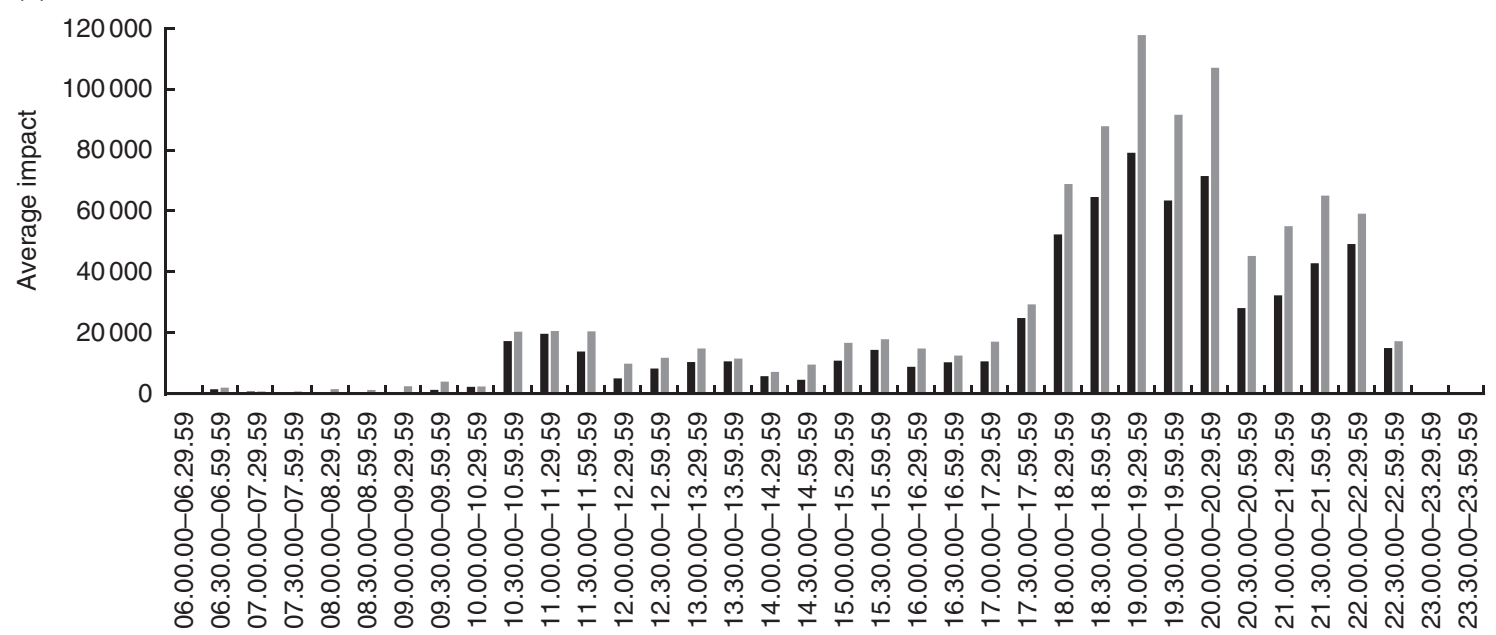

Hour of the day

Fig. 4 Unhealthy food advertising impact (number of advertisements $\times$ number of views) during (a) weekdays and (b) weekend days (all television channels combined) per half-hour (eight recording days, three major free-to-air channels) for adolescents aged 14-18 years, New Zealand, June-August 2015. Food advertisements restricted to be marketed to children by the WHO-Europe nutrient profiling system ${ }^{(19)}(\square)$; occasional food advertisements according to New Zealand Ministry of Health Food and Beverage Classification system ${ }^{(10)}$

(i.e. advertisements frequently incorporating promotional characters or premium offers). The majority of food advertising across all channels was found to be unhealthy. TV2, the channel sampled with the largest child audience, had the highest rate of unhealthy food advertising and food advertising overall. In addition, more than $80 \%$ of unhealthy food advertisements were shown during children's peak viewing times and a third of unhealthy food advertisements used either promotional strategies or premium offers that might appeal to children. A recent study found that children who watched just twenty television adverts per week for sugary breakfast cereals eat about $30 \%$ more of them than children who see none ${ }^{(25)}$.

The volume and nature of the advertising to which children are exposed on television suggest that industry self-regulation has not been effective in New Zealand. When roughly compared with the previous studies done in New Zealand, which included only selected hours during the day, the rate and proportion of unhealthy food advertising on television have not decreased over time ${ }^{(14-16)}$. One potential reason for this ineffectiveness is that the times where advertising is permitted or limited under self-regulation (during children's programmes) do not match children's actual viewing patterns. The findings of the present study suggest that this is the case, as child audience ratings data from A.C. Nielsen show that children's viewing reaches its highest peak in the evenings where no channel restrictions are in place. This means that there is no protection for children in place when they are most likely to be watching television and most likely to view unhealthy food advertisements. 
Improved regulations are needed in order to reduce the exposure of children to unhealthy food advertising in New Zealand, especially during their peak viewing times. The revised self-regulation code for advertising to children $^{(13)}$ proposes a small improvement in that it now includes a nutrient profiling system (the Ministry of Health Food and Beverage Classification System), but not the most appropriate one, which is the WHO-EU nutrient profiling model $^{(19)}$, as shown in the current study.

This WHO-EU model has previously been recommended as the best to restrict unhealthy food advertising to children in New Zealand based on a comparison of three nutrient profile models applied on a database of more than 13000 packaged food products in New Zealand ${ }^{(20)}$. The new code ${ }^{(13)}$ includes a provision to limit unhealthy food advertising during programming times when children comprise at least $25 \%$ of the total audience. This is not a logical definition to use because adult viewership is in the denominator (total audience); having more adults in the audience will reduce the percentage of children watching but not the total number or percentage of children watching. It would be recommended to define peak viewing times using audience ratings for children only. The present study has shown that a substantial reduction in impact could be achieved if unhealthy food advertisements would be restricted during times when at least $25 \%$ of total New Zealand children are watching television.

In order to assess compliance with the new draft code, once implemented, and to measure progress on reducing exposure of unhealthy food advertising to children, regular monitoring by the government or an independent agency, using similar processes as used in the current study, is needed. In addition, sanctions for companies that breach regulations could be applied, similar to policies in Quebec (Canada) and the UK. Tools used in these countries include issuing warnings and fines, removing the advertisement from air and publicly naming companies that breach regulations. The current complaints-based system in New Zealand focuses on whether the content of individual advertisements is offensive socially or morally. There are no publicly available materials aimed at informing television watchers that they can also complain about the placement, frequency or nutritional content of food advertisements, which is a likely reason for the low complaint levels around these issues.

\section{Strengths and limitations}

The present study is the largest study of food advertising on television conducted in New Zealand, covering eight days, three channels and a total of $432 \mathrm{~h}$ of television. The study is also the first to evaluate empirically the strengths and weaknesses of industry self-regulation, which previously have only been analysed qualitatively.

One limitation was that the study did not include other channels with children's programming. Most of those channels air on paid television. However, FOUR has free-to-air children's programming and its inclusion would have allowed for further evaluation of the effectiveness of self-regulation. It would have additionally been useful if the Nielsen data obtained used a larger sample of Māori and Pacific children so that comparisons could be drawn between population groups, given the large inequities in childhood obesity that exist between ethnic groups in New Zealand.

\section{Conclusions}

Responding effectively to childhood obesity is a major challenge facing decision makers in New Zealand and around the world. Ensuring that unhealthy foods are not marketed to children is one of the WHO's major policy recommendations for tackling unhealthy diets and contributing to the prevention of obesity and non-communicable diseases. The present study shows that the majority of food advertising on television in New Zealand is unhealthy and that most unhealthy food advertisements are specifically targeted at children. Current self-regulation is ineffective in protecting children from exposure to unhealthy food advertising. The WHO-EU nutrient profiling system needs to be used to restrict unhealthy food advertising to children on television, especially during their peak viewing times. In addition, a co-regulatory approach with independent monitoring could be implemented. To achieve this, efforts and consultations beyond the ASA's recent review of the advertising codes will be needed.

\section{Acknowledgements}

Financial support: This study was supported by the Health Research Council of New Zealand. The funder had no role in design, conduct, analysis, interpretation and write-up of the findings. Conflict of interest: S.V. is a Deputy Editor for Public Health Nutrition; the remaining authors report no conflict of interest. Authorship: S.V. and B.S. designed the study, A.S. collected the data, A.S. and S.V. analysed the data and wrote the manuscript, all authors critically revised draft versions of the manuscript. Ethics of buman subject participation: This study was approved by the Human Participants Ethical Committee of the University of Auckland. However, no human subjects were involved in this study.

\section{References}

1. Ministry of Health (2015) Annual Update of Key Results 2014/15: New Zealand Healthy Survey. Wellington: Ministry of Health.

2. World Health Organization (2016) Report of the Commission on Ending Childhood Obesity. Geneva: WHO.

3. Boyland EJ, Nolan S, Kelly B et al. (2016) Advertising as a cue to consume: a systematic review and meta-analysis of the effects of acute exposure to unhealthy food and nonalcoholic beverage advertising on intake in children and adults. Am J Clin Nutr 103, 519-533. 
4. Boyland EJ \& Whalen R (2015) Food advertising to children and its effects on diet: a review of recent prevalence and impact data. Pediatr Diabetes 16, 331-337.

5. Cairns G, Angus K \& Hastings G (2009) The Extent, Nature and Effects of Food Promotion to Children: A Review of the Evidence to December 2008. Geneva: WHO.

6. Cairns G, Angus K, Hastings G et al. (2013) Systematic reviews of the evidence on the nature, extent and effects of food marketing to children. A retrospective summary. Appetite 62, 209-215.

7. Kraak VI, Vandevijvere S, Sacks G et al. (2016) Progress achieved in restricting the marketing of high-fat, sugary and salty food and beverage products to children. Bull World Health Organ 94, 540-548.

8. Advertising Standards Authority (2010) Children's Code For Advertising Food. http://www.asa.co.nz/codes/codes/ childrens-code-for-advertising-food/ (accessed June 2013).

9. ThinkTV (2011) Advertising on Television. Getting it right for children. http://www.thinktv.co.nz/wp-content/uploads/ Booklet_Mar_2011.pdf (accessed October 2013).

10. Ministry of Health (2007) Food and Beverage Classification System for Years 1-13: User Guide. http://weightmanagement. hiirc.org.nz/assets/legacy/files/FB\%20Classification/heha-userguide-years1-13.pdf (accessed April 2017).

11. Vandevijvere S \& Swinburn B (2015) Getting serious about protecting New Zealand children against unhealthy food marketing. N Z Med J 128, 36-40.

12. Galbraith-Emami $S$ \& Lobstein $T$ (2013) The impact of initiatives to limit the advertising of food and beverage products to children: a systematic review. Obes Rev 14, 960-974.

13. Advertising Standards Authority (2016) Report on the review of the Children's Code for Advertising Food and the Code for Advertising to Children. http://www.asa.co.nz/ codes/codes/new-children-young-peoples-advertising-code/ (accessed October 2016).

14. Jenkin G, Wilson N \& Hermanson N (2009) Identifying 'unhealthy' food advertising on television: a case study applying the UK Nutrient Profile model. Public Health Nutr 12, 614-623.
15. Wilson N, Quigley R \& Mansoor O (1999) Food ads on TV: a health hazard for children? Aust N Z J Public Health 23, 647-650.

16. Wilson N, Signal L, Nicholls S et al. (2006) Marketing fat and sugar to children on New Zealand television. Prev Med $\mathbf{4 2}$, 96-101.

17. Kelly B, King L, Baur L et al. (2013) Monitoring food and non-alcoholic beverage promotions to children. Obes Rev 14, Suppl. 1, 59-69.

18. Kelly B, Halford JCG, Boyland EJ et al. (2010) Television food advertising to children: a global perspective. Am J Public Health 100, 1730-1736.

19. World Health Organization (2015) WHO Regional Office for Europe nutrient profile model. http://www.euro.who.int/en/ health-topics/disease-prevention/nutrition/publications/2015/ who-regional-office-for-europe-nutrient-profile-model-2015 (accessed May 2015).

20. Mhurchu CN, Mackenzie T \& Vandevijvere S (2016) Protecting New Zealand children from exposure to the marketing of unhealthy foods and drinks: a comparison of three nutrient profiling systems to classify foods. $N Z$ Med J 129, 41-53.

21. National Institute for Health Innovation (2011) Nutritrack. Reformulation of processed foods to promote health. http:// www.foodandhealth.auckland.ac.nz/en/about/news/news2014/2014/05/nutritrack.html (accessed May 2015).

22. Lumley J, Martin J \& Antonopoulos N (2012) Exposing the Charade: The Failure to Protect Children from Unhealthy Food Advertising. Melbourne: Obesity Policy Coalition.

23. Kraak VI \& Story M (2015) Influence of food companies' brand mascots and entertainment companies' cartoon media characters on children's diet and health: a systematic review and research needs. Obes Rev 16, 107-126.

24. Jenkin G, Madhvani N, Signal L et al. (2014) A systematic review of persuasive marketing techniques to promote food to children on television. Obes Rev 15, 281-293.

25. Longacre MR, Drake KM, Titus LJ et al. (2016) Child-targeted TV advertising and preschoolers' consumption of highsugar breakfast cereals. Appetite 108, 295-302. 